\title{
Analysis on the Influence of the Age Factor on Second Language Acquisition: Rethink the Meaning of Critical Period Hypothesis and Create New Teaching Methods
}

\author{
Haoyi Zhang \\ Faculty of Arts and Social Sciences, University of Sydney, Sydney, the NSW, Australia, 2006 \\ ${ }^{*}$ Corresponding author. Email: haoy_zhang@yahoo.com
}

\begin{abstract}
In recent years, parents have transferred anxiety to their children. This also causes some learners to be exposed to a second language and start to learn it at an early age. However, it still reminds to be explored whether this can be more conducive to learners' improvement in their language ability. This paper analyzes the influence of age on second language acquisition (SLA) from the perspective of critical period hypothesis (CPH) and brain function lateralization. Based on the existing research, this paper puts forward the practical application and teaching methods beneficial to students. This paper holds that the age of learning has a direct impact on the phonetic learning of second language acquisition (SLA), but its impact on other aspects of second language acquisition is not clear. Therefore, age factor has become the main research direction of this paper.
\end{abstract}

Keywords: Second Language Acquisition (SLA), Critical Period Hypothesis (CPH), Teaching Methods, Teaching English to Speakers of Other Languages (TESOL), Age of language learners (AOL)

\section{INTRODUCTION}

The relevant theories of critical period hypothesis have been studied all the time, and the conclusions are different. This hypothesis has an important impact on the research and development of second language acquisition. Creating new learning methods through this hypothesis is an effective practice of this theory. This paper attempts to put forward some views through four parts. The first part is the theoretical part, which includes the interpretation of keywords, such as second language learning, critical period hypothesis and the age of language learners. The second part is the research of some past scholars on the age of language learners and their acceptance degree in recent years [1]. This part mainly selects three academic papers from different directions for analysis. The third part is the introduction and purpose explanation of the critical period hypothesis, so that educators can understand what benefits learners can get from this theory, and then reflect it in practice. Finally, new teaching methods will be developed and some methods that are more helpful to learners will be mentioned. The main significance of this study is that it can help learners effectively grasp the best period of learning a second language, thus reducing their pressure and eliminating the anxiety of young learners' parents.

\section{BACKGROUND INFORMATION OF THE RESEARCH ON SLA}

Age, as one of the SLA variables, is the easiest factor to be understood by readers relative to other factors [3]. Critical period refers to a period of time in an organism's life. During this period, some external conditions will have stronger impact on the organism than at other times. After the "lateralization" of the human brain, the second language learning will be negatively affected. [9]. Therefore, it is the best to learn a language before the brain completes marginalization, which is the so-called "critical period of language learning" [14]. In 1959, two biologists, Penfield and Roberts, first proposed the meaning of $\mathrm{CPH}$ [6] [16]. At first, this hypothesis was only applicable to first language learners. Later, Lennebery extended the $\mathrm{CPH}$ into the field of second language acquisition in 1967 [5]. Moreover, some scholars believed that SLA was also restricted by physiology factor [2]. The research that informs this theory is brain lateralization [15]. In other words, not only does language acquisition have 
something to do with brain's cognitive ability, but also it is connected with the age before puberty [8]. After the critical period, it is difficult for the second language to reach a high level [15]. It can be hard to acquire a second language after the brain is rewired, therefore, it is preferable to learn it from infancy through adolescence [5]. By comparing second language learners in different countries, Johnson and Newport (1987) finds that the age at which good learning results are most likely to be achieved is preschool, that is, 7-8 years old [4].

\section{RESEARCH ON WHETHER AGE FACTOR AND CPH THEORY HAS AN INFLUENCE ON SLA}

\subsection{The relationship between $\mathrm{CPH}$ theory and SLA}

There are some linguists believe that $\mathrm{CPH}$ is flawed, because in the actual learning situation, some adult second language learners can approach native language learners [4]. Qingxin (2012) gives the example of Bialystok (1989), by dividing learners into two groups according to the age of 15 , he concluded that age is not the main factor for the difference in second language acquisition. Bialystok believes that there is a functional relationship between the ability to learn a language and the language itself. Deng and Zhu (2016) also believe that whether second language learning is related to age is uncertain, because the maturity of the nervous system lags adolescence.

The meaning of the critical period of second language development should be analyzed from the perspectives of vocabulary, pronunciation, syntax and listening comprehension. Qingxin (2012) said that although it is still controversial whether $\mathrm{CPH}$ has an impact on second language acquisition, the impact of $\mathrm{CPH}$ on pronunciation can be determined. Although there is no unified conclusion on the specific time of brain lateralization, its positive impact on pronunciation has been positively recognized [4]. In the critical period of second language acquisition, living in the target language country or chatting with native speakers can effectively improve oral expression ability [5].

\subsection{The relationship between age factor and SLA}

In recent years, many language researchers have made investigations and studies on second language learners, and their conclusions have a far-reaching impact on second language learning. According to Stölten et al. (2015), it is found that only investigating second language learners before puberty will have a negative impact on the study age and the field of second language acquisition. Therefore, the age before puberty should not be used as a key hypothetical period [18]. His experiment selected 41 subjects whose mother tongue was Dutch, and the second language was Spanish. The subjects were divided into two groups, aged 1 to 11 and 13 to 19 . The language start time is regarded as the numerator and the single duration as the denominator. The difference in pronunciation and intonation was quantified as a percentage [22]. The language application ability of second language learners was observed by controlling the initial age of learning a second language. Other conditional variables of the experimental sample were controlled unchanged.

This experiment fills the gap in the previous experiment, that is, the mother tongue of the experimental sample is an adhesive language family, while the target language does not belong to an adhesive language family. Mother tongue and second language belong to the same language system in this experiment. This further supports the existence of age effect [11].

Saito (2015) believes that second language learners' grammar and vocabulary skills will improve with the accumulation of second language learning experience, but it has nothing to do with age. Oral English is affected by the time of starting learning [8]. Eighty-eight native Japanese speakers were tested in pronunciation, intonation, grammar, vocabulary, stress and other aspects. As shown in Figure 1, taking the age of language acquisition (AOA) as the horizontal axis and the overall stress and intelligibility scores as the vertical axis, the linear correlation scattering distribution map is drawn, and the data are analyzed by quantitative research method.

Through the data, the author concludes that age plays an important role in second language acquisition, while grammar and vocabulary do not. The significance of this experiment is that through the comprehensive test of second language learners, the experimenter can effectively prove the importance of age factors [10]. However, this experiment also has deviations. For example, his subjects are native Japanese speakers. Secondly, the experimental participants are older than 15 years old, close to the maximum value of $\mathrm{CPH}$. Third, the conclusions of this experiment are not compared with L1 and L2. However, this experiment is still closely related to the theme of this paper. 

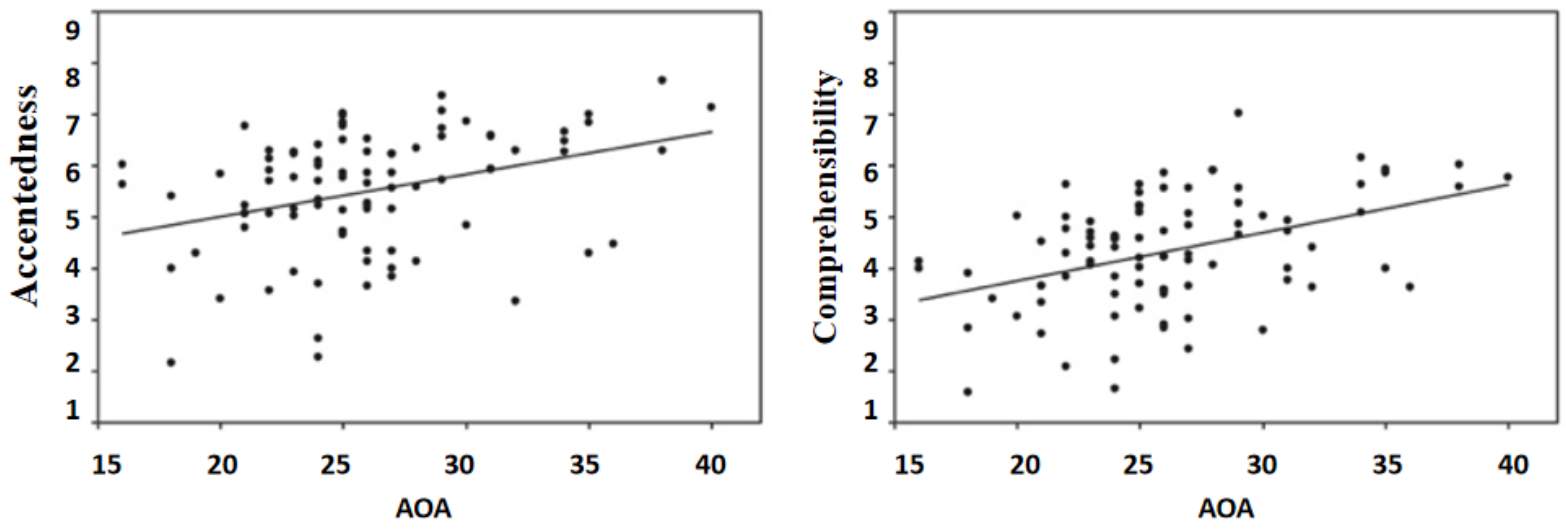

Figure 1 Global accentedness and comprehensibility scores (1=little accent, easy to understand, 9=heavily accented, hard to understand) plotted as a function of AOA.

The last experiment cited in this paper comes from Cox (2017). By selecting 43 elderly people over 65 years old as experimental research samples, the author uses quantitative research methods to analyze the interaction between variables and comes to the conclusion that the elderly have a higher success rate in second language learning. Cox (2017) believes that experimenters improve their academic performance by using explicit grammar training, which is helpful to learn another new language. Cox proposed that age is only a critical period or maturity, not a process extending to the whole life cycle in the early stage of its research [21]. Phonological cognition can regulate the second language learning of the elderly. The most important contribution of this experiment is that Cox (2017) proved the learning ability of the elderly, whether there is $\mathrm{CPH}$ or not. Language teaching can be realized through explicit teaching (EI) and implicit teaching [21]. This intervention for learners is useful.

\section{ABILITIES THAT CAN BENEFIT SECOND LANGUAGE LEARNERS}

Age is an objective and unchangeable feature for language learners. However, there are other factors: motivation, cognitive ability, and language acquisition, which can be changed. In this section, we will discuss the abilities that learners can improve and benefit from $\mathrm{CPH}$.

\subsection{Linguistic learning ability}

Language learning is the most core and direct ability, among which the language coding ability is the most significantly improved in the learning process. It is effective to ensure new accuracy and language rhythm [12]. For example, make a face like a rabbit to make $/ F /$ sound, and calculate the previous paragraph by tapping the rhythm of the hand. Through repeated practice, we can achieve the effect of automatic planning and pronunciation.

\subsection{Cognitive ability}

Cognitive ability has also been improved. The improvement of fragments and upper fragments can effectively improve the fluency of the second language, and implicit memory ability is an important factor to predict its level [13]. Implicit learning ability and implicit memory ability interact [20] [23]. Therefore, language learners' cognitive ability can be improved through this kind of training. In addition, second language learners can improve their language reflection ability by comparing the differences between the target language and their mother tongue. Cognition and self-cognition also affect language ability. The focus is to grasp the characteristics of each learning stage to formulate targeted training and learning.

\subsection{Effective communicating ability}

Second language learners can improve their confidence through effective communication in the classroom [1]. By mastering the key period of language phonetics, learners can reduce the mistakes made in communication with others. According to Al Mortada, there is a correlation between self-confidence and motivation. Learners' learning patterns will evolve over time.

\section{NEW TEACHING METHODS}

Practice has proved that both qualitative and quantitative research methods are effective. Due to the differences in the learning basis of the experimental samples, the final test results are not accurate. The effectiveness of the actual method will be achieved through two comparisons, which are divided into pre-intervention and post-intervention. As shown in the figure below, the author selected freshmen majoring in English as a sample to conduct an oral English test. The corresponding result sums up two kinds of data respectively by teaching process and results. 
In this part, qualitative research methods are adopted [7] [17] [19]. First observe and test the performance of sample learners before intervention to compare the results. Mainly observe the initial level of sample learners. Then conduct two hours of correction segmentation to identify super segmentation and self-monitoring teaching activities. Finally, the experimental results are compared with the initial data. Type test meetings shall be held in different forms. Firstly, the questionnaire was divided into 100 copies and distributed to each sample learner in the form of five-point Likert scale and two short questions. In addition, interviews with 10 sample learners were recorded. The interview questions are mainly about the experience and feelings of the sample learners. In addition, the trace log will also be used for the effectiveness of this practice. The diary will be distributed to sample learners and reviewed and summarized at the end of the exercise [7]. As the conclusion of qualitative research, it is considered effective to complete a five-point Likert scale and two short questions, and the teaching results will be affected by the key period to a certain extent [7].

\section{CONCLUSION}

In general, this paper makes a series of introductions, and analysis on how to apply them to practice from theory to recent experiments. Age is a personal factor affecting second language acquisition. $\mathrm{CPH}$ is based on age. After the critical period hypothesis was put forward, it has been controversial. This hypothesis gives information that the SLA ability is affected by age, the best of which is before puberty. Recently, scientists have proved that age is inversely proportional to final achievement. Only in the experimental stage can theoretical and experimental data have an impact on it. As for the application of critical period hypothesis, although it may cause some confusion for early English teachers, it can still improve English learners' expression. Some practical oral classroom activities and teachers' intervention make up for the regret in the critical period. In short, the purpose of this paper is not to deny the existence of the critical period in second language learning, but to prove the negative impact of the critical period on language, intonation and rhythm. The age of the critical period is unknown.

\section{ACKNOWLEDGMENTS}

This article was written at a time when COVID-19 was sweeping the world, and all academics, educators and workers were facing unprecedented challenges. In particular, there were more challenges for education industry, such as moving from face-to-face teaching to online teaching in order to meet social distancing guidelines. The prevention of COVID-19 has become an important social issue, so a heartfelt thanks is expressed to the front-line protesters, as well as those who are dedicated to the cause of medicine and education.

\section{REFERENCES}

[1] Al-Murtadha, M. (2020). Increasing EFL learner self-confidence with visualization tasks. ELT Journal, 74(2), 166-174.

[2] Hopp, H., \& Schmid, M. S. (2013). Perceived foreign accent in first language attrition and second language acquisition: The impact of age of acquisition and bilingualism. Applied psycholinguistics, 34(2), 361-394.

[3] Dong, G., \& Ren, H. (2013). The role of age in second language acquisition-a psychological perspective. British Journal of English Linguistics, 1(1), 1-6.

[4] DENG, F., \& ZHU, L. Q. (2016). An analysis of critical period hypothesis in english teaching. Sino-US English Teaching, 13(2), 116-122.

[5] Alamri, S. (2015). Language Acquisition and the Critical Period Hypothesis.

[6] Ren, J. (2017). Reflecting on the Primary Phonetic Learning Based on the Critical Period Hypothesis in Language Acquisition. Theory and Practice in Language Studies, 7(10), 900-906.

[7] Engh, D. (2013). Why Use Music in English Language Learning? A Survey of the Literature. English Language Teaching, 6(2), 113-127.

[8] Saito, K. (2015). The role of age of acquisition in late second language oral proficiency attainment. Studies in Second Language Acquisition, 37(4), 713-743.

[9] Klein, D., Mok, K., Chen, J. K., \& Watkins, K. E. (2014). Age of language learning shapes brain structure: a cortical thickness study of bilingual and monolingual individuals. Brain and language, 131, 20-24.

[10] Archila-Suerte, P., Zevin, J., \& Hernandez, A. E. (2015). The effect of age of acquisition, socioeducational status, and proficiency on the neural processing of second language speech sounds. Brain and language, 141, 35-49.

[11] Foster, P., Bolibaugh, C., \& Kotula, A. (2014). Knowledge of nativelike selections in a L2: The influence of exposure, memory, age of onset, and motivation in foreign language and immersion settings. Studies in Second Language Acquisition, 36(1), 101-132. 
[12] Pickering, L. (2012). Second language speech production. The Routledge handbook of second language acquisition, 335-348.

[13] Granena, G., \& Long, M. H. (2013). Age of onset, length of residence, language aptitude, and ultimate L2 attainment in three linguistic domains. Second Language Research, 29(3), 311-343.

[14] Sang, Y. (2017). A Conceptual Review of Age Effect on L2 Acquisition. Journal of Education and Practice, 8(9), 1-4.

[15] Qingxin, Z. (2012). Is there a critical period for second language acquisition.

[16] Abello-Contesse, C. (2009). Age and the critical period hypothesis. ELT journal, 63(2), 170-172.

[17] Ron, C. (2015). Relationship between the Phonetic Aspect of Second Language Acquisition and Age: Testing on the Critical Period Hypothesis in a Selected Function of Language. The annals of Gifu Shotoku Gakuen University. Faculty of Foreign Languages, 54, 15-28.

[18] Stölten, K., Abrahamsson, N., \& Hyltenstam, K. (2015). Effects of age and speaking rate on voice onset time: The production of voiceless stops by near-native L2 speakers. Studies in Second Language Acquisition, 37(1), 71-100.

[19] Andringa, S. (2014). The use of native speaker norms in critical period hypothesis research. Studies in Second Language Acquisition, 36(3), 565-596.

[20] Saito, K. (2015). The role of age of acquisition in late second language oral proficiency attainment. Studies in Second Language Acquisition, 37(4), 713-743.

[21] Singleton, D., \& Pfenninger, S. E. (2019). Exploring a poorly understood variable: An agenda for classroom research on the age factor. Language Teaching, 52(1), 111-127.

[22] Suwartono, S. (2014). Enhancing the pronunciation of English suprasegmental features through reflective learning method. TEFLIN Journal, 25(1), 80-93.

[23] Granena, G. (2019). Cognitive aptitudes and L2 speaking proficiency: links between LLAMA and HI-LAB. Studies in Second Language Acquisition, 41(2), 313-336. 